\title{
SPECTRUM OF APPENDICEAL LESIONS IN A TERTIARY REFERRAL CENTRE FOR A PERIOD OF ONE YEAR
}

\author{
Kokila $K^{1}$, Rajesh Nataraj A. P2, Narmadha R², Bharathi Vidhya Jayanthi ${ }^{4}$
}

${ }_{1}^{1}$ Assistant Professor, Department of Pathology, Government Tiruvannamalai Medical College \& Hospital, Tiruvannamalai, Tamilnadu, India.

2Senior Assistant Professor, Institute of Pathology, Madras Medical College, Chennai, Tamilnadu, India.

3 Senior Assistant Professor, Institute of Pathology, Madras Medical College, Chennai, Tamilnadu, India. ${ }^{4}$ Director and Professor, Institute of Pathology, Madras Medical College, Chennai, Tamilnadu, India.

\section{ABSTRACT}

\section{BACKGROUND}

Non neoplastic lesions of appendix outnumber the neoplastic counterparts and appendicitis is the frequently encountered lesion in day to day clinical practice. Both non-neoplastic and neoplastic lesions of appendix present with abdominal pain and thus imaging \& histopathological examination of the specimen play an important role in diagnosing the specific entities. In this study, we analysed the macroscopic and microscopic features of the appendicectomy specimen during the study period and ascertained the frequency of non-neoplastic and neoplastic lesions of the appendix.

\section{METHODS}

During the study period i.e. from January 2017 to December 2017, patients who underwent appendicectomy either as an emergency, or an elective procedure, in Madras Medical College \& Rajiv Gandhi Government General Hospital, Chennai, were included in the study population. The patient particulars and the histopathological diagnosis were retrieved from the surgical pathology records.

\section{RESULTS}

We received 1100 appendicectomy specimens and all were subjected to routine histopathological examination. The histopathological spectrum of appendiceal lesions ranged from non-neoplastic to neoplastic lesions. Non-neoplastic lesions accounted for $99.4 \%$ of cases (1093 cases) and remaining $0.6 \%$ of cases ( 7 cases) were neoplasms. Various non-neoplastic conditions like acute appendicitis, acute suppurative appendicitis, chronic appendicitis, eosinophilic appendicitis, fibrosing appendicitis, granulomatous lesion, appendicitis with worm infestation were reported. In this study, primary appendiceal neoplasms like carcinoid tumour, low grade appendiceal mucinous neoplasm (LAMN) and mucinous adenocarcinoma of the appendix were encountered.

\section{CONCLUSIONS}

All appendicectomy specimens should be subjected to routine histopathological examination as certain incidental findings might be missed if histopathological examination of the specimens was not performed.

HOW TO CITE THIS ARTICLE: Kokila K, Nataraj RAP, Narmadha R, et al. Spectrum of appendiceal lesions in a tertiary referral centre for a period of one year. J. Evolution Med. Dent. Sci. 2019;8(16):1292-1297, DOI: 10.14260/jemds/2019/288

\section{BACKGROUND}

The most common cause for acute abdomen in all age groups is appendicitis and an appendicectomy is one of the most frequently performed surgical procedure worldwide.(1,2) Delayed diagnosis of appendicitis could lead to complication like perforation of appendix, peritonitis, sepsis leading to increased morbidity and mortality. $(3,4)$ Though non-neoplastic lesions outnumber the neoplastic counter parts, appendiceal neoplasms are also frequently encountered and these may be a primary or secondary neoplasm involving the appendix.

'Financial or Other Competing Interest': None.

Submission 27-02-2019, Peer Review 09-04-2019,

Acceptance 16-04-2019, Published 22-04-2019.

Corresponding Author:

Dr. Rajesh Nataraj A. $P$,

Flat-4, Vinayak Apartments, Plot-1149/1151,

II ${ }^{\text {nd }}$ Main Road,Poombukar Nagar,

Kolathur, Chennai-600099, Tamilnadu, India.

E-mail:aprn75@gmail.com

DOI: $10.14260 /$ jemds $/ 2019 / 288$

(c) ()$_{\mathrm{BY}} \mathrm{NC}$

\section{Aims and Objectives}

1. To analyse the histopathological nature of various non-neoplastic and neoplastic lesions of appendix.

2. To ascertain the frequency with which these lesions occur.

\section{METHODS}

This is a retrospective study. The demographic data and the histopathological findings of patients who underwent appendicectomy at Madras Medical College \& Rajiv Gandhi Government General Hospital, Chennai, between January 2017 and December 2017 were retrieved from the surgical records. Our study population included all patients who underwent appendicectomy for appendicitis and appendicectomy in other circumstances. A detailed macroscopic examination of the specimens were performed, and all these specimens were subjected for routine histopathological examination.

\section{RESULTS}

A total of 1100 specimens were received during the study period and non-neoplastic lesions accounted for $99.4 \%$ of cases ( 1093 cases) and remaining $0.6 \%$ of cases ( 7 cases) were neoplastic lesions. 


\begin{tabular}{|c|c|c|}
\hline Histopathological Diagnosis & $\begin{array}{c}\text { Number } \\
\text { of Cases } \\
\text { Reported }\end{array}$ & $\begin{array}{c}\text { Percentage } \\
\text { of Cases }\end{array}$ \\
\hline Acute appendicitis & 557 & $50.5 \%$ \\
\hline Acute suppurative appendicitis & 149 & $13.5 \%$ \\
\hline Chronic appendicitis & 225 & $20.4 \%$ \\
\hline Follicular appendicitis & 71 & $6.4 \%$ \\
\hline Eosinophilic appendicitis & 8 & $0.8 \%$ \\
\hline Obliterative appendicitis & 8 & $0.8 \%$ \\
\hline Fibrosing appendicitis & 33 & $3 \%$ \\
\hline Gangrenous appendicitis & 5 & $0.5 \%$ \\
\hline Appendicular abscess & 24 & $2.2 \%$ \\
\hline Perforated appendicitis & 2 & $0.2 \%$ \\
\hline Appendicitis with worm infestation & 7 & $0.7 \%$ \\
\hline Granulomatous lesion & 1 & $0.1 \%$ \\
\hline Endometriosis & 1 & $0.1 \%$ \\
\hline Carcinoid & 2 & $0.2 \%$ \\
\hline Mucosal hyperplasia & 2 & $0.2 \%$ \\
\hline $\begin{array}{c}\text { Low grade appendiceal mucinous } \\
\text { neoplasm }\end{array}$ & 3 & $0.2 \%$ \\
\hline Mucinous adenocarcinoma & 2 & $0.2 \%$ \\
\hline Total & 1100 & $100 \%$ \\
\hline \multicolumn{3}{|c|}{$\begin{array}{l}\text { Table 1. Histopathological Spectrum of Appendiceal } \\
\text { Lesions }\end{array}$} \\
\hline
\end{tabular}

\begin{tabular}{|c|c|c|c|}
\hline Histopathological Diagnosis & $\begin{array}{l}\text { Number } \\
\text { of Males }\end{array}$ & $\begin{array}{c}\text { Number of } \\
\text { Females }\end{array}$ & Total \\
\hline Acute appendicitis & 358 & 199 & 557 \\
\hline Acute suppurative appendicitis & 62 & 87 & 149 \\
\hline Chronic appendicitis & 123 & 102 & 225 \\
\hline Follicular appendicitis & 35 & 36 & 71 \\
\hline Eosinophilic appendicitis & 2 & 6 & 8 \\
\hline Obliterative appendicitis & 3 & 5 & 8 \\
\hline Fibrosing appendicitis & 21 & 12 & 33 \\
\hline Gangrenous appendicitis & 4 & 1 & 5 \\
\hline Appendicular abscess & 18 & 6 & 24 \\
\hline Perforated appendicitis & - & 2 & 2 \\
\hline $\begin{array}{l}\text { Appendicitis with worm } \\
\text { infestation }\end{array}$ & 3 & 4 & 7 \\
\hline Granulomatous lesion & 1 & - & 1 \\
\hline Endometriosis & - & 1 & 1 \\
\hline Carcinoid & - & 2 & 2 \\
\hline Mucosal hyperplasia & - & 2 & 2 \\
\hline $\begin{array}{l}\text { Low grade appendiceal } \\
\text { mucinous neoplasm }\end{array}$ & 1 & 2 & 3 \\
\hline Mucinous adenocarcinoma & 1 & 1 & 2 \\
\hline Total & 632 & 468 & 1100 \\
\hline
\end{tabular}

Among non-neoplastic lesions histological variants of appendicitis like acute appendicitis, acute suppurative appendicitis, chronic appendicitis, fibrosing appendicitis, obliterative appendicitis, follicular appendicitis, eosinophilic appendicitis, gangrenous appendicitis, appendicular abscess, perforated appendicitis and appendicitis with Enterobius Vermicularis infestation were reported. A case of granulomatous lesion was also reported among the nonneoplastic spectrum. Endometriosis of the appendix was reported in a 32-year-old female who presented with acute abdominal pain. Mucinous lesions of appendix ranged from Mucocele, Low grade appendiceal mucinous neoplasm and Mucinous adenocarcinoma of the appendix.

\begin{tabular}{|c|c|c|c|}
\hline $\begin{array}{c}\text { Age } \\
\text { Group }\end{array}$ & Number of Males & $\begin{array}{c}\text { Number of } \\
\text { Females }\end{array}$ & $\begin{array}{c}\text { Percentage } \\
\text { of Cases }\end{array}$ \\
\hline $10-20$ & 119 & 61 & 180 \\
\hline $21-30$ & 319 & 223 & 542 \\
\hline $31-40$ & 96 & 122 & 218 \\
\hline $41-50$ & 79 & 34 & 113 \\
\hline $51-60$ & 15 & 22 & 37 \\
\hline $61-70$ & 4 & 6 & 10 \\
\hline Total & $\mathbf{6 3 2}$ & $\mathbf{4 6 8}$ & $\mathbf{1 0 0 \%}$ \\
\hline \multicolumn{3}{|c|}{ Table 3. Age Wise Distribution of Cases } \\
\hline
\end{tabular}

In this study, males constituted $57.5 \%$ of cases $(632$ males) and females accounted for $42.5 \%$ of cases (468 females). Non neoplastic lesions were common in the second decade and as age advances neoplastic lesions like Low grade appendiceal mucinous neoplasm and Mucinous adenocarcinoma of the appendix were encountered.

Appendicitis with Enterobius vermicularis infestation was observed in the first decade of life and no gender predilection was observed ( 3 cases in 10-20 age range, 2 cases in 21-30 and 2 cases in 30-40 age range). A case of granulomatous lesion was observed in a 36-year-old male and endometriosis of their appendix was encountered in a 32-year-old female patient.

Mucinous lesions of the appendix were common in the $4^{\text {th }}, 5^{\text {th }}$ and $6^{\text {th }}$ decades of life and showed no gender predilection. 2 cases of mucosal hyperplasia were reported in females \& 51-60 was the age range. 2 cases of Low grade appendiceal mucinous neoplasm were reported in females in their $6^{\text {th }}$ decade and one case in the $5^{\text {th }}$ decade who was a male patient.

The clinical presentation of non-neoplastic and neoplastic lesions showed no much difference as all these patients presented with abdominal pain. In most cases, emergency appendicectomy was done and radiological imaging was not available. A case of low grade appendiceal mucinous neoplasm (LAMN) presented with right inguinal hernia with mucinous cystadenoma of the appendix as content. Another case of low grade appendiceal mucinous neoplasm presented with pseudomyxoma peritonei.

Mucinous adenocarcinoma of the appendix was reported in one female patient aged 69 years and another case was encountered in a 62-year-old male patient. No other primary tumour was identified, and they found to have primary mucinous adenocarcinoma of the appendix.

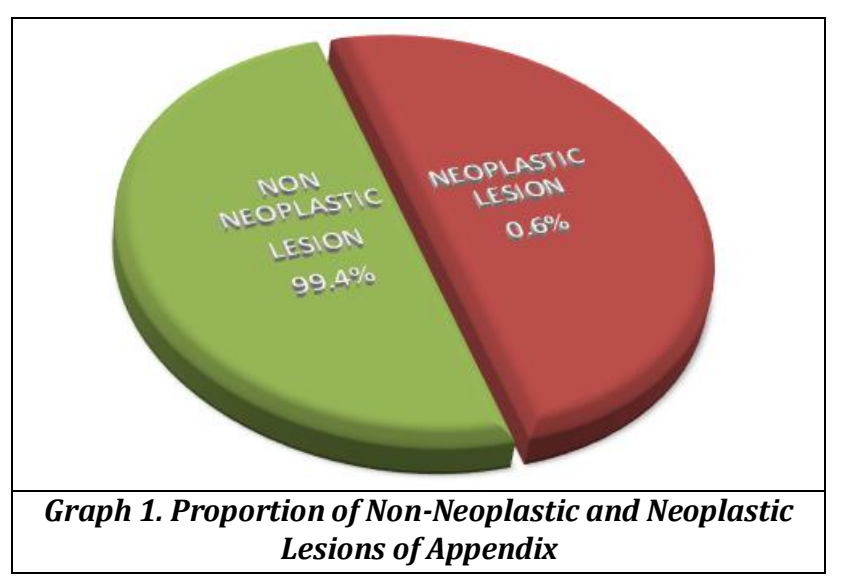




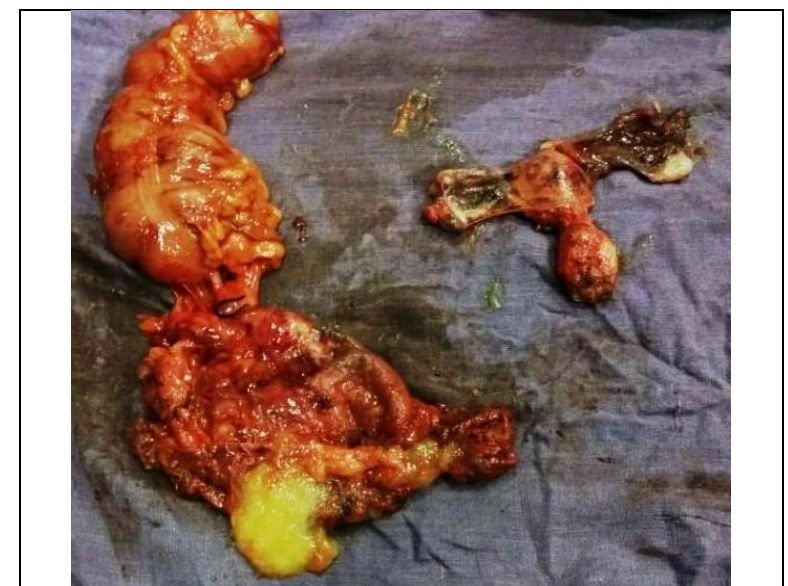

Figure 1. Cystically Dilated Appendix (Ruptured Cyst with Mucoid Material as Its Content) with Adhesions to the Ascending Colon with Hysterectomy and Salphingo-Oophorectomy Specimen
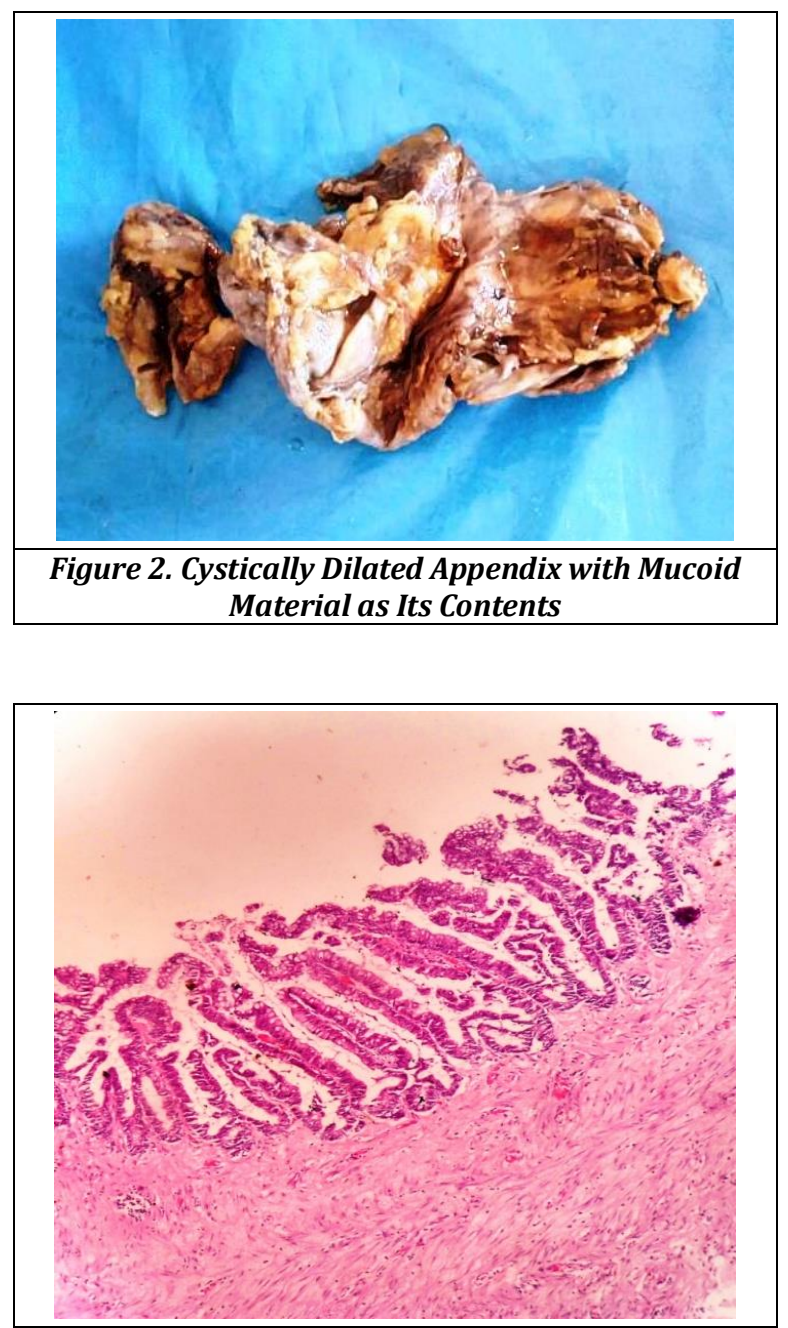

Figure 3. Low Grade Appendiceal Mucinous Neoplasm- The Fibrotic Cyst Wall Lined by Tall Columnar Mucinous Epithelium- H \& E- 400X
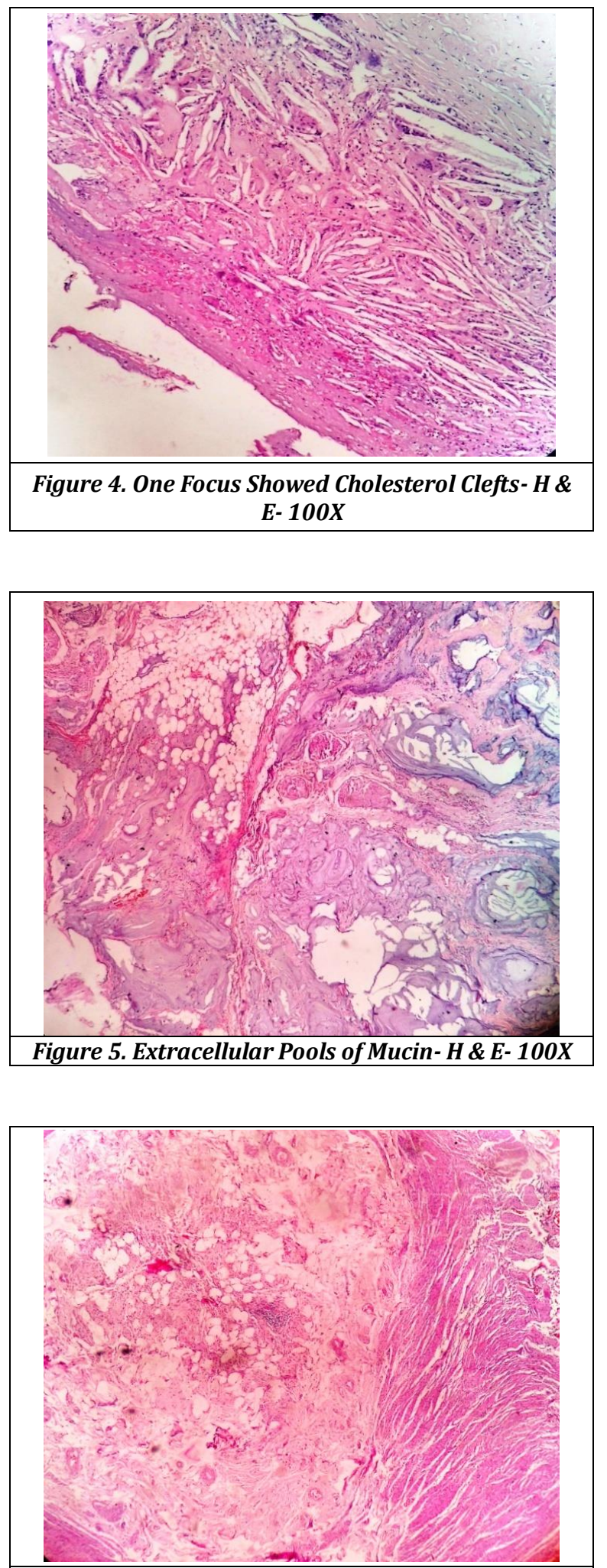

Figure 6. Adjacent Appendix of LAMN Showed Features of Fibrosing Appendicitis- $\mathrm{H} \& \mathrm{E}-100 \mathrm{X}$ 

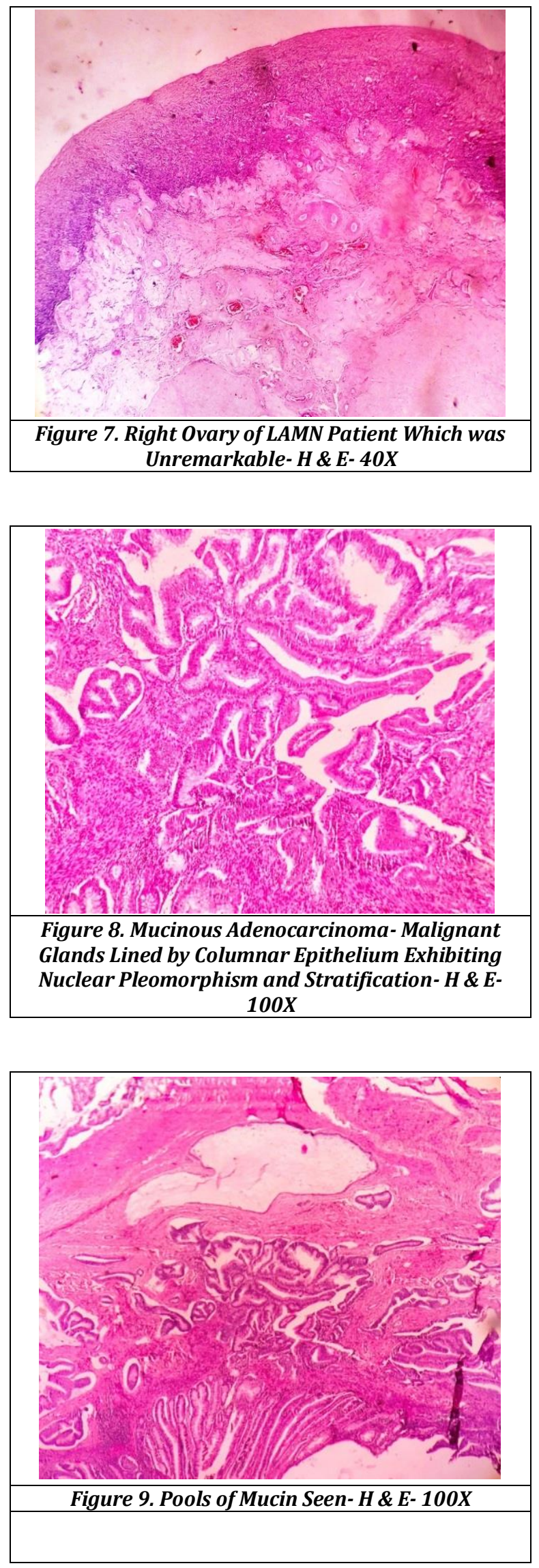
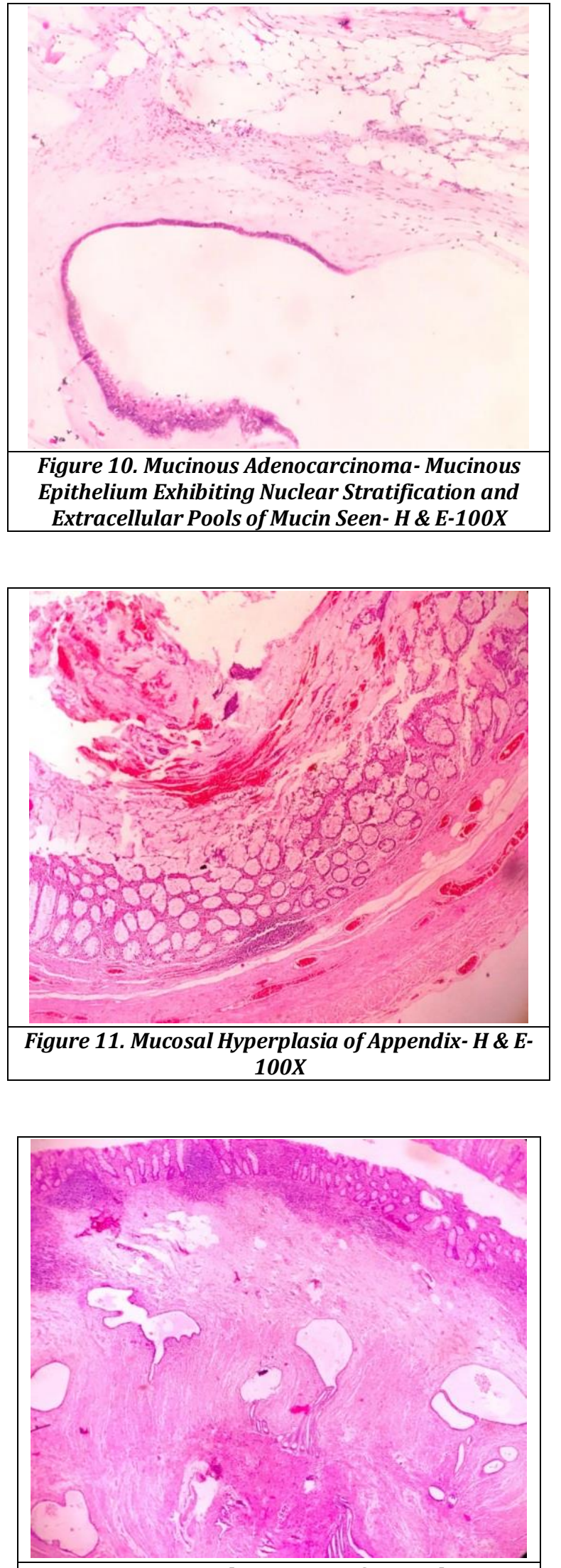

Figure 12. Endometriosis of Appendix-

Endometrial Glands and Stroma Seen- $\mathrm{H} \& \mathrm{E}-40 \mathrm{X}$ 

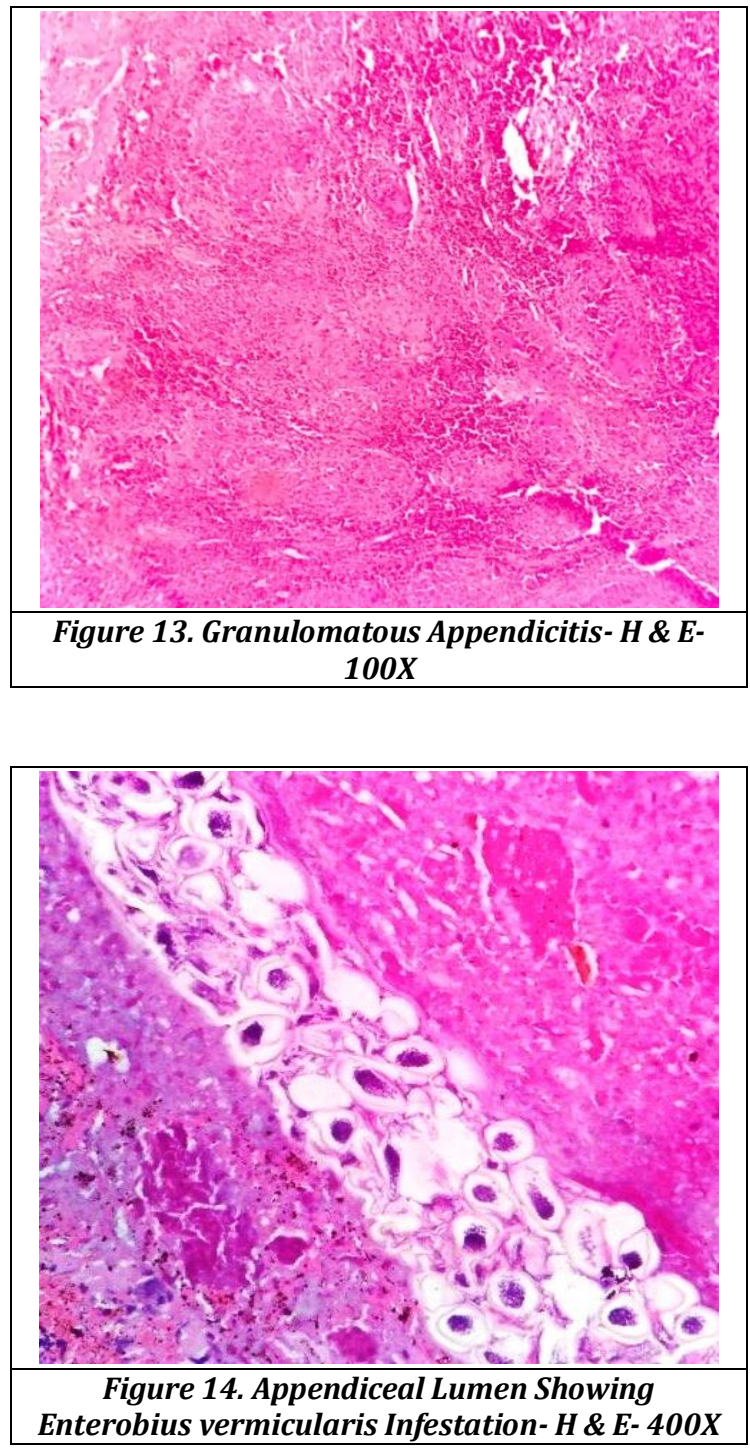

\section{DISCUSSION}

One of the most frequent indication for surgical intervention is acute abdominal pain and appendicectomy was the most frequently performed surgery.(5,6) The peak incidence of acute appendicitis occurs between the ages of 10 and 30 years and this parallels that of lymphoid development. Before puberty there was no gender predilection for acute appendicitis, yet the frequency gradually increases in males after puberty, by the age of 15 to 25 years, the sex ratio shifts to 2:1 in favor of men.(7) This bias decreases with age, and the incidence again becomes equal. The lifetime incidence of acute appendicitis is estimated to be $7 \%$ overall, with $8.6 \%$ for men and $6.7 \%$ for women. $(8,9,10)$

In this study, acute appendicitis accounted for $50.5 \%$ of cases (557 cases). The peak incidence of acute appendicitis occurred in the second decade and males were affected more commonly than females (358 were males and 199 were females). Most patients presented with acute abdominal pain and underwent emergency appendicectomy.

Other forms of appendicitis like acute suppurative appendicitis, chronic appendicitis, fibrosing appendicitis, obliterative appendicitis, follicular appendicitis, eosinophilic appendicitis, gangrenous appendicitis, appendicular abscess, perforated appendicitis were reported.

The association of Enterobius vermicularis infection with appendicitis was first reported in the late $19^{\text {th }}$ century, with the presence of the organism being related to the appendix lumen. The rates of inflammation in appendices infested with these pinworms has ranged from 13\% to $37 \%$. (11) The incidence of worm infestation in appendicectomy specimens of patients with presumed appendicitis have ranged from $0.2 \%$ to $41.8 \%$. In this current series, the incidence of appendicitis with worm infestation (0.6\%) was similar to that of other studies.

Granulomatous appendicitis may be discovered incidentally in a patient with a clinical presentation of acute appendicitis. The incidence ranged from $1.3 \%$ to $2.3 \%$ in under developed countries and $0.14 \%$ to $0.3 \%$ in developed countries.(12,13) Granulomatous appendicitis can be caused by various infectious and non-infectious factors. Systemic conditions like Crohn's disease and sarcoidosis may also be associated with granulomatous inflammation of the appendix. Infectious causes include Mycobacterium tuberculosis, Yersinia species, Blastomycosis, Schistosoma species, Actinomyces species, Campylobacter species and Histoplasma capsulatum. We reported a case of granulomatous appendicitis which was an incidental finding and patient was further investigated and treated for tuberculosis.

Endometriosis was a frequent cause of lower abdominal pain in women of reproductive age group. The sites involved in descending order were ovaries, uterine ligaments, rectovaginal septum, cul de sac, pelvic peritoneum, large and small bowel, appendix, mucosa of the cervix, vagina and fallopian tubes and laparotomy scars.(14) Thus, endometriosis in gastrointestinal tract was rare and occurs only in $10 \%$ of women with endometriosis. Most intestinal endometriosis occurs in the rectum and sigmoid colon, and occurrence in the appendix was rare. Appendiceal endometriosis was usually asymptomatic, although it can occasionally cause appendicitis, perforation and intussusception. In this study, we reported a case of appendiceal endometriosis in a 32-year-old female who presented with acute abdominal pain.

In the present study, mucinous lesions of appendix were reported ranging from mucocele to primary mucinous adenocarcinoma of appendix. First described in 1842, mucocele was an obstructive dilatation of the appendix resulting from intraluminal accumulation of mucoid material.(11) The incidence of this condition in appendicectomy specimen has been reported as $0.2 \%$ to $0.7 \%$.

Primary malignancies of the appendix were rare entites and noted only in almost $0.9-1.4 \%$ of the appendicectomy specimens.(15) The most common primary appendiceal neoplasms include Carcinoid, Adenocarcinoma, Goblet cell carcinoma, Signet ring cell carcinoma.

Carcinoid tumour was considered to be the most common type of primary appendiceal tumour and accounts for $60 \%$ of all appendiceal tumours and most often they were incidental. The majority of appendiceal carcinoids were benign and metastases were rare. The most important prognostic indicator for appendiceal carcinoid was the tumour size and increased tumour size was associated with a remarkably increased risk of metastasis. Therefore, appendiceal carcinoid tumour more than $2 \mathrm{~cm}$ was usually managed by right hemicolectomy.(16,17) 2 cases of carcinoid 
were reported and both were incidental findings and were less than $2 \mathrm{cms}$.

Mucoceles were rare entities and affect women four times as often as men and peak age of incidence was usually after 50 years.(18) Four histological types of appendiceal mucocele have been described: retention cyst, mucosal hyperplasia, mucinous cystadenoma and mucinous cystadenocarcinoma. However, adenocarcinomas of the appendix were more often seen in men in the sixth or seventh decades.(19) Prospective clinical diagnosis of mucinous neoplasms were often difficult. Half of the cases were asymptomatic, detected incidentally and are often stable for many years(20).Other cases can present with abdominal pain, weight loss, nausea and vomiting, palpable mass, acute appendicitis, intussusception and localized rupture or peritoneal spread.

In this study, 2 cases of mucosal hyperplasia were reported in female patients in their fifth decade and both cases presented as acute abdominal pain. Low grade appendiceal mucinous neoplasm accounted for $0.2 \%$ of cases ( 3 cases- 2 were female and one was a male patient). One case presented as right inguinal hernia with mucinous cystadenoma as the content and underwent right hemicolectomy. Another case presented with pseudomyxoma peritonei and underwent hysterectomy with salpingo-oophorectomy. The ovaries were unremarkable. 2 cases of mucinous adenocarcinoma were encountered, and one patient was male and other was a female patient. Both were diagnosed around $6^{\text {th }}$ decade. Secondaries to appendix were ruled out by thorough clinical examination and both tumours were positive for CK 20 positive and CK 7 was negative.

\section{CONCLUSIONS}

The incidence of appendicitis was high in the second decade of life and was the most common entity encountered. In this study, we diagnosed incidental neoplastic lesions like carcinoid tumour, and hence, routine histopathological examination of the appendicectomy specimen is essential. Unusual or co-existing pathologies though rarely seen, their final confirmation can be done only on histopathology. A thorough clinical, radiological and pathological examination of the appendicectomy specimen is required to rule out rare and incidental findings.

\section{REFERENCES}

[1] Omiyale AO, Adjepong S. Histopathological correlations of appendectomies: a clinical audit of a single center. Ann Transl Med 2015;3(9):119.

[2] Shrestha R, Ranabhat SR, Tiwari M. Histopathologic analysis of appendectomy specimens. Journal of Pathology of Nepal 2012;3:215-9.

[3] Hale DA, Molloy M, Pearl RH, et al. Appendectomy: a contemporary appraisal. Ann Surg 1997;225(3):25261.

[4] Zoarets I, Poluksht N, Halevy A. Does selective use of computed tomography scan reduce the rate of "white" (negative) appendectomy? Isr Med Assoc J 2014;16(6):335-7.
[5] Marudanayagam R, Williams GT, Rees BI. Review of the pathological results of 2660 appendicectomy specimens. J Gastroenterol 2006;41(8):745-9.

[6] Swank HA, Eshuis EJ, Ubbink DT, et al. Is routine histopathological examination of appendectomy specimens useful? A systematic review of the literature. Colorectal Dis 2011;13(11):1214-21.

[7] Emre A, Akbulut S, Bozdag Z, et al. Routine histopathologic examination of appendectomy specimens: retrospective analysis of 1255 patients. International Surgery 2013;98(4):354-62.

[8] Zdichavsky M, Gögele H, Blank G, et al. Histological characterization of appendectomy specimens with intraoperative appearance of vascular injection. Surg Endosc 2013;27(3):849-53.

[9] Khairy G. Acute appendicitis: is removal of a normal appendix still existing and can we reduce its rate? Saudi J Gastroenterol 2009;15(3):167-70.

[10] Seetahal SA, Bolorunduro OB, Sookdeo TC, et al. Negative appendectomy: a 10-year review of a nationally representative sample. Am J Surg 2011;201(4):433-7.

[11] Akbulut S, Tas M, Sogutcu N, et al. Unusual histopathological findings in appendectomy specimens: a retrospective analysis and literature review. World J Gastroenterol 2011;17(15):1961-70.

[12] AbdullGaffar B. Granulomatous diseases and granulomas of the appendix. Int J Surg Pathol 2010;18(1):14-20.

[13] Tucker ON, Healy V, Jeffers M, et al. Granulomatous appendicitis. Surgeon 2003;1(5):286-9.

[14] Kumar V, Abbas AK, Aster JC. Robbins \& Cotran Pathologic Basis of Diseases. 9th edn. Philadelphia, United States: Elsevier Health Sciences 2014.

[15] Rajesh C, Kulbhushan S, Somraj M, et al. Low-grade appendiceal mucinous neoplasm: a lesser known entity with significant morbidity: case report. JOJ Case Stud 2017;2(1):555578.

[16] Shapiro R, Eldar S, Sadot E, et al. Appendiceal carcinoid at a large tertiary center: pathologic findings and long-term follow-up evaluation. Am J Surg 2011;201(6):805-8.

[17] In't Hof KH, van der Wal HC, Kazemier G, et al. Carcinoid tumour of the appendix: an analysis of 1 , 485 consecutive emergency appendectomies. J Gastrointest Surg 2008;12(8):1436-8.

[18] Madwed D, Mindelzun R, Jeffrey RB JR. Mucocele of the appendix: imaging findings. AJR Am J Roentgenol 1992;159(1):69-72.

[19] Carr N, Sobin L. Tumours of the appendix. In: Bosman FT, Carneiro F, Hruban RH, et al. eds. WHO Classification of tumours of the digestive system. World Health Organization classification of tumours. Vol. 3. 4th edn. Lyon, France: IARC Press 2010: p. 1225 .

[20] Dixit A, Robertson JH, Mudan SS, et al. Appendiceal mucocoeles and pseudomyxoma peritonei. World J Gastroenterol 2007;13(16):2381-4. 